\title{
Los peligros de la probabilidad y la estadística como herramientas para la valoración jurídico-probatoria
}

\author{
The hazards of using probability and statistics \\ like tools for legal assessment
}

Os perigos da probabilidade e da estatística como ferramentas para a valoração probatória-jurídica

\section{Ana Sánchez-Rubio ${ }^{1}$}

Universidad Pablo de Olavide - Sevilla/España

asanrub@upo.es

http://orcid.org/0000-0002-2027-8232

\begin{abstract}
RESUMEN: En el uso corriente de la expresión, probar significa comprobar, verificar, para de este modo, poder demostrar. El proceso penal, en aras de conseguir una demostración más próxima a la certeza o, como suele expresarse en el lenguaje jurídico, a la verdad material, cada vez con más frecuencia recurre a herramientas del campo matemático para dotar de mayor fuerza al resultado probatorio. En este sentido, la probabilidad derivada de la estadística está ocupando un papel protagonista. Este artículo pretende poner de manifiesto los riesgos que conlleva para la valoración judicial confiar plenamente en estos datos numéricos ya que, en ocasiones, las partes los exponen haciendo uso de interpretaciones erróneas que pueden llegar a condicionar la motivación de la sentencia. PalABRAs-Clave: prueba; verosimilitud; probabilidad lógica; probabilidad estadística; teorema de Bayes.
\end{abstract}

ABSTRACT: In the common use of the expression, to prove means to test, to check, as a way of demonstrating. These days, the criminal proceedings, in order to achieve the nearest demonstration to the certainty or, in legal language, to

1 Profesora Ayudante Doctora - Departamento de Derecho Público - Área de Derecho procesal - Universidad Pablo de Olavide - Sevilla/España 
the material truth, uses some tools of mathematical field for giving more strength to evidentiary result. In this regard, the probability product of statistics is increasingly occupying a major role. This paper aims to reveal the hazards that involve trusting completely of numerical data in legal assessment, particularly if the parties of the proceedings misinterpret mathematical results, since that could seriously influence on the judicial decision foundation.

KEYWORDs: evidence; credibility; logic likelihood; statistical probability; Bayes's theorem.

RESUMO: Em seu uso comum, provar significa comprovar, verificar, para desse modo, poder demonstrar. No processo penal, com o objetivo de conseguir uma demonstração mais próxima da certeza ou, como se costuma expressar em linguagem jurídica, à verdade material, cada vez com maior frequência se recorre a ferramentas do campo da matemática para fortalecer o resultado probatório. Nesse sentido, a probabilidade derivada da estatística está ocupando um papel de protagonismo. Este artigo pretende expor os perigos causados à decisão judicial pela confiança plena nesses dados numéricos já que, algumas vezes, as partes partem a sua exposição de interpretações erradas, o que pode chegar a determinar a motivação judicial.

PALAVRAs-ChAVE: prova; verossimilhança; probabilidade lógica; probabilidade estatística; teorema de Bayes.

SUMARIO: Introducción; 1 . La relación entre prueba, verosimilitud y probabilidad; 1.1. La verosimilitud; 1.2. La probabilidad; a. La probabilidad estadística; b. La probabilidad lógica; 2 . Herramientas de cálculo en la valoración judicial; 2.1. La teoría de la probabilidad bayesiana; 2.2. La aplicación de la estadística al ámbito probatorio; Consideraciones finales; Referencias bibliográficas.

\section{INTRODUCCIÓN}

Por todos es sabido que en el proceso subyace una imposibilidad práctica que obstaculiza la búsqueda de la verdad. Existen, por ejemplo, limitaciones legales asumidas respecto al uso de los medios judiciales de conocimiento y a los procedimientos con los que aquellos pueden 
ser producidos y utilizados; limitaciones temporales en la búsqueda de fuentes y en la proposición de pruebas ${ }^{2}$; y existen también restricciones económicas que impiden practicar ciertas diligencias que, quizás, pudieran acercarnos más a la realidad de los hechos ${ }^{3}$. De ahí la necesidad de distinguir entre una «verdad procesal», más limitada de lo que sucedió en la realidad ${ }^{4}$, y una «verdad histórica o material», plenamente coincidente

2 Así lo recoge, entre otros, Caprioli, cuando afirma que: «No hay duda de que el proceso penal sufre límites cognitivos que con frecuencia impiden al juez alcanzar una afirmación verdadera. La estrucutra misma del proceso es intrínsecamente contraria a la episteme: hay tiempos que respetar, preclusiones, prescripciones». (CAPRIOLI, F., Verità e giustificazione nel processo penale, Revista Brasileira de Direito Processual Penal, Porto Alegre, vol. 3, n. 1, 2017, p. 323) (traducción libre).

3 Hay otros muchos otros aspectos del proceso, como, por ejemplo, la necesidad de corregir la decisión sobre los hechos que permite a las partes limitar el ámbito de los hechos jurídicos a determinar, para mostrar cómo bajo muchos aspectos el proceso no es capaz de funcionar como mecanismo para determinar la verdad de los hechos. Respecto a ello, vid., ad exemplum: CALAMANDREI, Il giudice e lo storico, trad. SENTÍS MELENDO, en Estudios sobre el proceso civil, Buenos Aires, 1945, p. 112 y ss.; WEINSTEIN, J. B., Some Difficulties in Devising Rules for Determining Truth in Judicial Trials, Col. L. Rev. 66, 1966, p. 1115 y ss.; ALCHOURRÓN, C., BULYGIN, E., Los límites de la lógica y el razonamiento jurídico, en Análisis lógico y derecho, Centro de Estudios Constitucionales, Madrid, 1991, p. 311 y ss.

4 En este sentido lo expresa López Ortega al aseverar que: «El proceso tiene como fin el descubrimiento de la verdad, pero el conocimiento al que aspira el proceso penal es un conocimiento limitado y, consiguientemente, la verdad que pretende hallar es también una verdad limitada. Una verdad que sólo puede afirmarse alcanzada si se han observado las reglas establecidas para su comprobación, una verdad normativa que sólo puede ser verificada por la observancia de las reglas de procedimiento, que una vez comprobada no puede ser desmentida, que se encuentra convalidada por normas y que únicamente lo es si es buscada y conseguida respetando los procedimientos legales». (LÓPEZ ORTEGA, J. J., Información y justicia: la dimensión constitucional del principio de publicidad judicial y sus limitaciones, en Justicia y medios de comunicación, Consejo General del Poder Judicial, Madrid, 2007, p. 103). En consonancia con esta idea, sostiene Ferrer Beltrán cuando habla de las limitaciones que encuentra la prueba procesal frente al resto de pruebas que puedan llevarse a cabo al margen de un proceso judicial, que: «El primer tipo de limitaciones tiene que ver con el marco en el que se desarrolla la actividad probatoria y en el que el juez o tribunal tiene que decidir posteriormente acerca de los hechos probados. [...] La segunda limitación procesal que incide de un modo relevante sobre la relación entre prueba y verdad es la institución de la cosa juzgada. [...] La tercera limitación a las posibilidades de conocer la verdad 
con lo ocurrido en el hecho que se investiga pero inalcanzable tanto en el plano jurídico como fuera de él.

Debido a estas dificultades, los ordenamientos jurídicos más avanzados no consideran que la búsqueda de la verdad «absoluta» sea la finalidad del proceso. En el mundo occidental, donde todo es falible y cuestionable y donde prima la celeridad y el pragmatismo frente la autenticidad $^{5}$, la relación prueba-verdad hace alusión a la posibilidad de alcanzar una verdad limitada. Es decir, el proceso se conforma con obtener una verosimilitud suficiente de los hechos a través de una adecuada actividad probatoria. Sin embargo, como veremos con más detalle infra, al sistema judicial no le basta con una verosimilitud en términos de posibilidad -aptitud, potencia u ocasión para ser o existir algo- sino de probabilidad - fundada apariencia de verdad ${ }^{6}-$.

En este sentido, hasta hace unos años el razonamiento judicial hacía uso de una probabilidad que extraía como consecuencia de inferencias que, obtenidas a través de la lógica deductiva, le permitían llegar a una conclusión debidamente fundada ${ }^{7}$. No obstante, de un tiempo a esta parte se ha querido ir un paso más allá: las partes ansían poder aportar los resultados de las pruebas en términos de probabilidad matemática -razón entre el número de casos favorables y el número de casos posibles ${ }^{8}-$,

acerca de - las proposiciones sobre - los hechos en el proceso judicial viene representada por la existencia en todos los ordenamientos jurídicos modernos de una apreciable cantidad de reglas jurídicas sobre la prueba». (FERRER BELTRÁN, J., Prueba y verdad en el derecho, Marcial Pons, Madrid, 2005, p. 57-60).

5 Ya en 1947 apuntaba Carnelutti al respecto «[...] el proceso de búsqueda sujeto a normas jurídicas, que restringen y deforman su pureza lógica, no puede ser sinceramente considerado como un medio para el conocimiento de la verdad de los hechos, sino como una fijación o determinación de los propios hechos, que puede coincidir o no con la verdad de los mismos y es absolutamente independiente de ello». CARNELUTTI, F., La prueba civil, trad. ALCALÁ-ZAMORA Y CASTILLO, Depalma, Buenos Aires, 1982, p. 30).

6 Definiciones extraídas de la primera acepción del Diccionario de la Real Academia Española.

7 Sobre el razonamiento jurídico vid., entre otros, PERELMAN, C., La lógica jurídica y la nueva retórica, Civitas, Madrid, 1988, y GRAJALES, A., Argumentación jurídica, Astrea, Buenos Aires, 2014.

8 Definición extraída de la tercera acepción del Diccionario de la Real Academia Española. 
pues consideran que así tendrán un mayor peso probatorio. Este deseo encuentra su máxima expresión en la prueba pericial y, en concreto, en la pericia de conocimientos técnicos o científicos, que es la más susceptible de ser presentada mediante resultados numéricos. Ahora bien, la interpretación de estos cálculos no siempre es correcta, por lo que es necesario dominar los razonamientos de la estadística para no realizar una valoración errónea de la prueba judicial.

Con el propósito de exponer las diferencias entre los distintos grados de certidumbre que exige el Derecho para considerar un hecho como probado y, asimismo, de alertar de los riesgos que conlleva un análisis superficial de los cálculos estadísticos en el campo jurídico, este artículo se estructura en dos bloques principales. Por un lado, se abordará la relación que existe entre conceptos muy similares pero en absoluto sinónimos, como son el de verosimilitud y el de probabilidad. Además, dentro de este último, veremos las diferencias que separan a la probabilidad lógica de la probabilidad estadística. Por otro lado, en relación con este tipo de probabilidad se expondrá el funcionamiento de uno de los teoremas más recurrentes en el sistema probatorio -el teorema de Bayespara, posteriormente, destacar los peligros que acarrea malinterpretar sus conclusiones a la hora de enjuiciar un caso. Finalmente, cerraremos este trabajo con algunas conclusiones al respecto.

\section{LA RELACIÓN ENTRE PRUEBA, VEROSIMILITUD Y PROBABILIDAD}

La exclusión de la verdad «absoluta» del conjunto de los objetivos alcanzables en la determinación judicial de los hechos nos sitúa en el ámbito de la incertidumbre, es decir, de conocimientos y juicios de los que únicamente se puede decir, en línea de principio, que no tienen una fundamentación absoluta, completa e indiscutible. Frente a esta situación, la reacción más común y difundida consiste en razonar, también a propósito de la determinación judicial del hecho, en términos de probabilidad ${ }^{9}$. Esto es, se dice que esta determinación, si no puede

9 Señala en este sentido Gascón Abellán cómo el hecho de que «que las condiciones y obstáculos teóricos e institucionales para alcanzar el conocimiento impidan hablar de «verdades absolutas» no invalida el modelo. Pone solo de 
fundamentarse en alguna verdad «absoluta», al menos puede conseguir un sustituto aceptable, constituido por alguna verdad «probable» ${ }^{10}$.

De esta manera, a mayor probabilidad que logre proporcionar una prueba, más próximos estaremos de la verdad «relativa» o verdad «procesal». En este sentido, conviene aclarar el cuadro de los equívocos terminológicos que concurren en el ámbito probatorio, matizando ciertos conceptos tan próximos como lo son el de «verosimilitud» y «probabilidad», en ocasiones tomados como sinónimos de «verdad». Tan solo teniendo claros estos conceptos podremos calificar el resultado que nos ofrece una prueba como verdadero, verosímil o probable.

\subsection{LA VEROSIMILITUD}

El término «verosimilitud» aparece a menudo vinculado al de «verdad»y confundido, en ocasiones, con el de «probabilidad» ${ }^{11}$. En aras de demarcar dicho término, aprecia Taruffo que, por una parte, se tiende a definir la verosimilitud de una aserción como su capacidad para representar una cierta realidad, como la aproximación de la representación al objeto representado o como la cercanía de una afirmación a la realidad a la que se refiere. Por ejemplo, es verosímil enunciar que la medida de un objeto es A, cuando en realidad la medida es B, si la distancia entre A y B es poco significativa. En virtud de esta definición, la verosimilitud indica, sustancialmente, el grado de capacidad representativa de una descripción respecto a la realidad ${ }^{12}$. Sin embargo, desde la óptica procesal,

manifiesto que hay que tomar conciencia del carácter limitado y no absoluto del conocimiento alcanzado, y que tal vez por ello sea preferible hablar de «probabilidad o conocimiento probable» en lugar de verdad». (GASCÓN ABELLÁN, M., Los Hechos en el Derecho. Bases argumentales de la prueba, Marcial Pons, Madrid, 2010, p. 58).

10 TARUfFO, M., La prueba de los hechos, Trotta, Madrid, 2011, p. 190-191.

11 CALAMANDREI, P., Il giudice e lo storico, trad. SENTÍS MELENDO, en Estudios sobre el proceso civil, Buenos Aires, 1945, p. 124 y ss.

12 Advierte Taruffo de que en la doctrina italiana el análisis del concepto de verosimilitud cae en una confusión, que fue introducida por Calamandrei y que no ha sido eliminada ni siquiera por la doctrina más reciente. Afirma el autor que «el equívoco es terminológico y, por tanto, conceptual. El aspecto terminológico consiste en partir del vocablo Wahrscheinlichkeit y traducirlo 
la referencia del juicio de verosimilitud no es la realidad, ya que ésta es inalcanzable en el proceso, sino una hipótesis que se formula acerca de ella y que se emplea como parámetro para valorar si una afirmación es o no verosímil ${ }^{13}$.

Por otro lado, el término «verosimilitud» sirve para designar aquel aspecto de una afirmación sobre un hecho en función del cual se puede decir que ésta se corresponde con una hipótesis plausible según el orden «normal» de las cosas, en una situación en la que esa afirmación no haya sido sometida todavía a verificación probatoria o demostrativa ${ }^{14}$. En otras palabras, se considera verosímil lo que corresponde con la normalidad de un cierto tipo de conductas o de acontecimientos. Por ejemplo, si normalmente desayuno todos los días en la misma cafetería a las nueve de la mañana, resulta verosímil que lo haya hecho el martes de la semana pasada y que lo vaya a hacer también el próximo jueves a esa hora.

Esta definición lleva implícito, tal y como sostuvo Wittgenstein en su segundo período de pensamiento, que para considerar verosímil un enunciado relativo a un cierto evento, sea necesario disponer de un conocimiento de fondo relativo a la normalidad con que ocurre ese evento $^{15}$. Utiliza Taruffo una clásica ilustración para evidenciar esta idea:

por «verosimilitud», sin tener en cuenta el hecho de que así se toma en consideración únicamente un área, y ni siquiera la más importante, del significado del término, olvidando otra en la que significa, en cambio, «probabilidad»». Aprecia, además, que este error lleva a reconducir al mismo concepto dos significados distintos: «a) según el primero, verosimilitud se refiere a algo que tiene «la apariencia de ser verdadero», afecta a la alegación del hecho y es una valoración independiente y preliminar respecto al procedimiento probatorio; b) en el segundo sentido, verosimilitud equivale a probabilidad, advirtiendo, sin embargo, que en el proceso la verosimilitud-probabilidad se usa como «sustituto de la verdad»». (TARUFFO, M., La prueba de..., ob. cit., p. 183-184).

13 En relación con este asunto afirma López Barja de Quiroga que «ya no se discute si hemos de obtener en el proceso penal la verdad hasta sus últimas consecuencias, sino si partiendo de la imposibilidad del conocimiento de la verdad absoluta se relativiza, más que la verdad a encontrar, el grado de suficiencia precisa. Basta la mera probabilidad, la verosimilitud». (LÓPEZ BARJA DE QUIROGA, J., Instituciones de derecho procesal penal, Mendoza, Cuyo, 2001, p. 252).

15 WITTGEnSteIn, L., Sobre la certeza, trad. por Isidoro Reguera, Gredos, Madrid, 2009, p. 422. 
solo si tengo algún conocimiento empírico respecto del color habitual de los cisnes, puedo considerar verosímil que el cisne que otros hayan visto, o que yo veré mañana, sea blanco. $\mathrm{Si}$, en cambio, el acontecimiento en cuestión es único e irrepetible, no podrá ser objeto de previsiones ${ }^{16}$. Esto es, el cisne negro es lo que no parece verosímil de acuerdo a los conocimientos normales sobre este tipo de aves. Luego, si nada se sabe de antemano respecto a aquello que se afirma - situación en la que se encuentra el juzgador de unos hechos en el proceso-, no será posible decir si el enunciado al que se alude es o no verosímil. Pero ello no impide determinar si ese enunciado es verdadero o falso, pues no existe ninguna correspondencia entre verosimilitud y verdad ${ }^{17}$.

Esta falta de identidad se debe a que un hecho que se considera verosímil perfectamente puede no haber sucedido, por cualquier motivo. Lo que significa que el enunciado que se refiere a ese hecho puede parecer verosímil pero ser falso, si la realidad de aquello que ha sucedido no se corresponde con lo que el enunciado narra. Así, si una persona dice haberme visto desayunar en la citada cafetería a las nueve de la mañana el pasado jueves, este enunciado sería verosímil para cualquier otra persona conocedora de mis hábitos. Pero, es posible que justo dicho jueves, por

16 Según Taruffo, «esto presenta evidentemente el problema de la circularidad intrínseca del concepto de verosimilitud, ya que sería necesario conocer la realidad representada para establecer la verosimilitud de la representación, pero si se conoce la realidad deja de ser interesante discutir si la representación es verosímil». De este modo, «el juicio de verosimilitud se puede formular sensatamente teniendo, por un lado, una descripción y, por el otro, una hipótesis (a menudo fundada sobre alguna concepción acerca el orden normal de las cosas) sobre la eventualidad de que exista una realidad parecida al objeto representado. Desde este punto de vista, la referencia del juicio de verosimilitud puede no ser la realidad, sino una hipótesis que se formula acerca de ésta y que se emplea como parámetro para valorar si una aserción es o no verosímil». (TARUFFO, M., La prueba de..., ob. cit., p. 186).

En este sentido, para Martínez Solano, «la verosimilitud es el grado en el que una teoría puede corresponder con los hechos. Esa medida está en función de que el contenido de verdad de la teoría supere su contenido de falsedad». Siguiendo a Popper, este autor sostiene que existen dos definiciones de la nocion de verosimilitud: «una se puede denominar cualitativa, en el sentido de que responde a la idea intuitiva de verosimilitud; la otra es la propiamente cuantitativa, porque da como resultado un valor numérico». (MARTÍNEZ SOLANO, J. F., El problema de la verdad en K.R. Popper: reconstrucción histórico-sistemática, Netbiblio, 2005, p. 182 y ss). 
las razones que fueren, desayunase en casa y no fuese a la cafetería en toda la mañana. Del mismo modo, puede ser verdadera una afirmación que parece inverosímil porque no corresponde a ningún criterio de normalidad. Es decir, volviendo al ejemplo de Taruffo, puede ser verdadero el enunciado de quien afirma haber visto un cisne negro, aunque no sea habitual ver un cisne de ese color ${ }^{18}$.

En síntesis, la verosimilitud de un enunciado es irrelevante desde el punto de vista del juicio sobre la verdad o falsedad de un hecho. Y carece radicalmente de toda trascendencia también en cuanto a las pruebas que se presentan en un juicio pues, sus resultados no han de ser verosímiles sino certeros, y dicha certeza es la que, en la mayoría de las ocasiones, viene limitada por los obstáculos expuestos supra. En este escenario de incertidumbre es donde aparece la idea probabilidad, tanto lógica como estadística ${ }^{19}$.

Así las cosas, puede afirmarse que en cualquier circunstancia en la que sea necesario dilucidar si el enunciado de un hecho es verdadero o es falso, es preferible basarse en probabilidades y no en un juicio de verosimilitud. La verosimilitud, pues, no expresa conocimientos o grados de conocimiento, ya que éstos son suministrados por los elementos de prueba sobre la alegación del hecho vertida por las partes ${ }^{20}$. Por lo que, las pruebas o, a mejor decir, el resultado probatorio no arroja verosimilitud, ni nos permite conocer la verdad «absoluta», sino tan solo aquella verdad

18 TARUFFO, M., Simplemente la verdad, Marcial Pons, Madrid, 2010, p. 106.

19 Sobre ello, apunta Luna Serrano que «en la estadística moderna el principio de máxima verosimilitud se ha convertido en una idea sencilla, para algunos incluso evidente. Después de todo, ¿quién puede oponerse a la afirmación de que entre todas las explicaciones posibles para los datos, se escogerá como la mejor aquella que hace a los datos observados los más probables?». (LUNA SERRANO, A., Acerca de las verdades presuntas que inducen certeza, en Estudios jurídicos en homenaje al profesor Manuel García Amigo, La ley, Madrid, 2015, p. 326).

20 En palabras de Calvo González, «El juicio de verosimilitud formulará criterio apreciando críticamente, mediante confirmaciones e informaciones, cuánto en las hipótesis fácticas y/o jurídicas propende a disminuir o aumentar, debilitar o reforzar, las probabilidades favorables o contrarias respecto de una efectiva ocurrencia o resultancia. La verosimilitud, en fin, expresa aquí la fe de creer ahora probable en espera de ver luego probado». (CALVO GONZÁLEZ, J., Verdades difíciles, control judicial de hechos y juicio de verosimilitud, Cuadernos electrónicos de filosofía del derecho, núm. 15, 2007, p. 3). 
«procesal» o «relativa». Lo que debemos determinar es si a dicha verdad puede llegarse a través de la probabilidad o no.

\subsection{LA PROBABILIDAD}

La probabilidad de que algo suceda o, lo que verdaderamente interesa al proceso, la probabilidad de que algo haya sucedido, no es más que la determinación del grado de fundamentación que puede atribuirse a la hipótesis de la existencia de un hecho ${ }^{21}$. Puesto que no es posible fundamentar un hecho en una verdad «absoluta», al menos puede conseguirse un sustituto aceptable, constituido por una verdad «probable» ${ }^{22}$. Así, el recurso a la probabilidad resulta un lugar común usado con frecuencia en la teoría de los medios de prueba y del resultado probatorio en cuanto respecta a su valoración ${ }^{23}$. En este contexto cabe diferenciar entre la probabilidad estadística y la probabilidad lógica ${ }^{24}$, ya que ambas tienen un papel preponderante en la motivación de las sentencias.

\section{A. LA PROBABILIDAD ESTADÍSTICA}

La idea principal que subyace en el concepto de probabilidad estadística es que, por medio del cálculo de probabilidades matemáticas, es posible determinar el índice numérico que debe atribuirse a un

21 TARUFFO, M., La prueba de..., ob. cit., p. 190.

22 CALAMANDREI, P., La genesi lógica della giustizia civile, Opere giuridiche, Morano, Napoli, 1965, p. 42; FERRAJOLI, L., Derecho y razón: teoría del garantismo penal, Trotta, Madrid, 1989, p. 246-249.

23 También existen quienes se posicionan en contra de la idea de la probabilidad, al definir a la misma con una connotación puramente negativa, ya que se tiende a definir como probable aquello que no es falso pero que tampoco es ciertamente verdadero. Vid, por todos, BUNGE, M., La ciencia: su método y su filosofía, Debolsillo, 2009, p. 65. Sin embargo, a nuestro parecer, así se cae en una realidad que solo puede llevar a equívocos. El porcentaje de probabilidad ha de ser considerado como aquel que designa el grado de confirmación de una hipótesis y no como aquel que no alcanza la verdad absoluta.

GONZÁLEZ ECHEVARRÍA, A., Crítica de la singularidad cultural, Anthropos, Barcelona, 2003, p. 48 y ss.; RAMÍREZ FIGUEROA, A., Transformación de la Epistemología Contemporánea. De la unidad a la dispersión, Universitaria, 2004, p. 61 y ss. 
determinado enunciado o hipótesis fáctica ${ }^{25}$. Cuando el enunciado versa sobre un hecho litigioso, los medios de prueba ofrecen los puntos de partida del cálculo, que se desarrolla, en la gran mayoría de los casos, siguiendo el teorema de Bayes. El resultado es un número entre 0 y 1 que, se supone, expresa el grado de fiabilidad del enunciado o hipótesis fáctica sobre la base de los medios de prueba considerados.

Este modo de pensar se ha vuelto bastante popular en algunas áreas de la teoría de la prueba, principalmente en aquella que proviene de la criminalística ${ }^{26}$. La principal razón parece ser que esta teoría da la impresión de ser objetiva y fidedigna en un terreno en el que el subjetivismo y la incertidumbre siempre están presentes. A menudo se cree que si algo se expresa con un número puede ser tomado como cierto, y que las evaluaciones subjetivas se vuelven más objetivas y garantizan estar bajo un mayor control. No es de extrañar que, por tanto, muchos confíen en las concepciones estadísticas de la prueba, sostengan teorías bayesianas y crean que el peso de la prueba debe ser expresado con números, aunque muy pocos sean realmente capaces de desarrollar los sofisticados cálculos necesarios para incorporar un tratamiento matemático de la prueba en los contextos judiciales ${ }^{27}$.

25 ESPEJO MIRANDA, I., Estadística descriptiva y probabilidad, Servicio de Publicaciones de la Universidad de Cádiz, Cádiz, 2006, p. 23.

26 LORUSSO, S., La prova scientifica, en GAITO, A., La prova penale, Utet, Torino, 2008, p. 310.

27 Vid. TARUFFO, M., La prueba de..., ob. cit., p. 32. En este sentido, sostiene Gascón Abellán que existe una «necesidad de introducir criterios generales [cuantitativos] de valoración de la prueba aptos para neutralizar la influenciabilidad emotiva de los jurados en cuanto jueces de hecho, así como por la ausencia de una obligación de motivación del veredicto que sirviera de contrapeso al principio de libre convicción; o quizás también porque en los últimos años la evolución de las técnicas de análisis de la forensic science ha proporcionado una amplísima gama de pruebas científicas de estructura probabilístico-estadística que pueden ser usadas en los más diversos supuestos, tanto civiles como penales; o simplemente porque la aparición de la obra de L. J. Cohen, The probable and the provable (1977), con su confrontación entre lo que él llama probabilidad pascaliana (matemática) y probabilidad baconiana (inductiva), ha suscitado la reflexión sobre la viabilidad de la primera como modo de racionalización del proceso judicial sobre hechos». Señala, además, esta autora que «el intento de llevar al proceso el cálculo matemático de probabilidades se ha operado fundamentalmente con la aplicación del teorema 


\section{B. LA PROBABILIDAD LÓGICA}

La probabilidad estadística recién mencionada suele ser considerada, por tanto, como un dato crucial que proporciona una seguridad superior al resultado probatorio. Sin embargo, esta probabilidad numérica por sí sola no nos llevaría a la verdad, siquiera «relativa» o «procesal» de los hechos. Para llegar a la misma la probabilidad estadística ha de ser cohonestada con una probabilidad lógica, es decir, con una relación existente entre las pruebas aportadas por las partes ${ }^{28}$. Dicha relación ha de extraerse en virtud del sentido común y de las máximas de experiencia judiciales. Esto es, la probabilidad lógica tiene la forma de un razonamiento inductivo con premisas singulares y una conclusión general. Constituye así, el apoyo que ciertos enunciados le prestan a otro, teniendo en consideración a lo largo de su inferencia los datos proporcionados por la probabilidad estadística ${ }^{29}$.

de Bayes a las inferencias jurídicas basadas en probabilidades subjetivas. De todas formas, y aunque el bayesianismo ha terminado convirtiéndose en una moda o incluso en una especie de ortodoxia teórica, sobre todo en el ámbito estadounidense, es de señalar que recientemente se han propuesto nuevos modelos matemáticos de valoración racional de las pruebas que, al igual que los modelos de la probabilidad inductiva o lógica, intentan superar o paliar las deficiencias del modelo bayesiano convencional. Es el caso del modelo de belief funtions, desarrollado por Shafer (1976), y el Evidentiary Value Model, desarrollado por los suecos Ekelöf, Halldén y Edman». (GASCÓN ABELLÁN, M., Los hechos en el derecho..., ob. cit., p. 145 y ss).

Si el modelo bayesiano utiliza un concepto de probabilidad matemática en términos de frecuencia etadísitca entre indicio y tema de prueba, la teoría de la probabilidad lógica entiende en cambio la probabilidad como un concepto que surge no del azar, sino de causas: la probabilidad de una hipótesis se apoya en su conexión lógica con las pruebas a través de reglas (causales) generales, y mide el grado de apoyo (inductivo) que las pruebas proporcionan a la hipótesis. Así es como su creador, L. J. Cohen define a este modo de razonar. Este autor, lleva a cabo una teoría de la probabilidad alternativa a la probabilidad matemática, que tiene precisamente una de sus principales razones de ser en la insuficiencia de esta última para dar cuenta de los procesos judiciales de prueba. Cohen intenta mostrar que si se analiza la prueba judicial en términos del cálculo matemático de probabilidades surgen problemas y paradojas difíciles de resolver, y que estos problemas desaparecen si se usa un concepto no matemático sino inductivo de probabilidad. Para profundizar sobre esta idea vid. COHEN, L. J., The probable and the provable, Clarendon Press, Oxford, 1977.

HACKING, I., El surgimiento de la probabilidad, Gedisa, Barcelona, 1995, p. 44. 
En lo que a ello concierne, ha de tenerse presente que la probabilidad lógica no busca la determinación cuantitativa de las frecuencias correspondientes a clases de eventos, sino que intenta racionalizar la incertidumbre correspondiente a la hipótesis sobre un hecho, reconduciendo su grado de fundamentación al ámbito de los elementos de confirmación o de prueba disponibles con relación a esa hipótesis ${ }^{30}$. Se puede hablar, pues, de un criterio de probabilidad lógica prevaleciente como estándar al que el juez debe atenerse en la determinación de si un hecho ha recibido o no suficiente confirmación probatoria ${ }^{31} \mathrm{y}$, por tanto, al establecer si ese enunciado puede o no considerarse como «verdadero» a los efectos de la decisión ${ }^{32}$. Por consiguiente, será el producto de contemplar ambas probabilidades, arrojadas por las distintas pruebas practicadas en juicio,

30 TARUFFO, M., La prueba de..., ob. cit., p. 224.

31 Conviene recordar en este punto que el estándar de prueba tiene la función de señalar a partir de qué umbral podemos considerar que el grado de credibilidad de una hipótesis es suficiente como para basar en ella la decisión. Establecer este umbral no es una cuestión epistemológica, sino política y moral: una determinada distribución de los riesgos del error. Lo deseado es establecer un estándar de prueba objetivo, es decir, formulado de manera que la determinación de si se ha cumplido o no una hipótesis sea independiente de las actitudes subjetivas del juzgador. Sin embargo, los estándares de prueba penales con los que cuentan la mayoría de los sistemas jurídicos no satisfacen este requisito. Tanto los estándares de la duda razonable, de origen anglosajón, como el de íntima convicción, característico de los sistemas continentales europeos, no son objetivos, en el sentido de que en última instancia remiten a actitudes del juzgador no controlables intersubjetivamente. Por ello, autores como Laudan han criticado estos estándares aduciendo que con base en los mismos «aparentemente, todo lo que importa es si habiendo oído a todas las pruebas, la creencia de los jueces es firme y sólida. Y si no es así, entonces debe votar la absolución. Los jueces ni tan siquiera explican lo que significa tener una duda razonable, manteniendo de manera vergonzosa que esta noción es auto-evidente [...]. Básicamente, en estas circunstancias, la duda razonable queda reducida a cualquier duda que un juez quiera utilizar para absolver a alguien». (LAUDAN, L., Por qué un estándar de prueba subjetivo y ambiguo no es un estándar, Doxa, Cuadernos de Filosofía del Derecho, núm. 28, 2005, p. 100).

32 Según Frosini, el establecimiento de la veracidad de un enunciado implica aceptar la veracidad de una hipótesis. En palabras de este autor, «en los juicios criminales, la acusación trata de desarrollar una hipótesis que incluye la culpa del acusado y encaja con todas las pruebas disponibles. En respuesta, el abogado defensor trata de construir una hipótesis que incluye la inocencia del acusado y también se adapta a todas las pruebas disponibles. A menudo ambas partes logran su propósito y, en tal situación, el caso se decide habitualmente 
lo que nos llevará a alcanzar una decisión más próxima a la realidad de los hechos, es decir, a la verdad «procesal».

Es por ello por lo que puede concluirse que la probabilidad lógica constituye una relación coherente entre dos enunciados, es decir, se identifica con el razonamiento que surge a partir de los elementos de juicio disponibles y que permite atribuir un valor abstracto, por ejemplo mayor credibilidad, a una hipótesis en lugar de a otra ${ }^{33}$. Se trata, por tanto, de construir una dialéctica inductiva para poder argumentar la decisión que va desde la implicación lógica (probabilidad 1) a la negación lógica (probabilidad 0$)^{34}$. Debido a ello también se conoce a la probabilidad lógica como probabilidad inductiva e incluso subjetiva, ya que mide la disposición de una persona a decantarse por un acontecimiento incierto en función de un conjunto racional de posibilidades. Esta probabilidad tiene un papel fundamental en la valoración de todo tipo de medios de prueba y, como se verá más adelante, especialmente cuando haya pruebas que basen sus resultados en datos estadísticos.

\section{HerRamientas de Cálculo en la valoración Judicial}

La filosofía de la ciencia ha concluido que la creencia en un conocimiento empírico capaz de proporcionar certezas incuestionables se desvaneció con el surgimiento del post-positivismo, ya que los avances científicos fueron demostrando que el mundo físico no está regido por leyes casuales, sino probabilísticas ${ }^{35}$. De este modo, lo que razonablemente

a favor de la hipótesis más coherente». (FROSINI, B., Le prove statistiche nel proceso penale e nel processo civile, Giuffrè, Milano, 2002, p. 45 y ss).

33 Al respecto, afirma Rivadulla Rodríguez que: «A lo más que aspira una teoría de la inferencia inductiva es a la determinación mecánica de la probabilidad lógica o grado de confrimación de una hipótesis $h$ en base al dato de experiencia e». (RIVADULLA RODRÍGUEZ, A., Probabilidad e inferencia científica, Anthropos, Barcelona, 1991, p. 72.)

34 GONZÁLEZ ECHEVARRÍA, A., La construcción teórica en antropología, Anthropos, Barcelona, 1987, p. 33 y ss.

35 Los avances tecnológicos posteriores a la teoría newtoniana, y en particular los de la física cuántica, al presentar una naturaleza gobernada por el principio de indeterminación, propician más bien la creencia de que «el mundo físico (atómico) no está regido por leyes causales, sino probabilísticas del 
se puede exigir es que las proposiciones inferidas de la experiencia se adopten como probablemente ciertas, reconociendo que pueden tener diferentes grados de seguridad ${ }^{36}$. En sintonía con esta idea, en el apartado anterior hemos convenido en que el conjunto de pruebas de que se dispone en un proceso permite, únicamente, atribuir un determinado grado de confirmación o de probabilidad de que la alegación vertida por la parte sea verdadera ${ }^{37}$-con las limitaciones ya señaladas respecto del concepto de «verdad»-.

En aras de concretar ese grado de confirmación en cifras, la mayoría de los intentos modernos de construir una teoría del razonamiento inferencial, que refleje el proceso de justificación del

tipo “si x entonces y en un porcentaje z". Por lo demás, si el razonamiento empírico inductivo propio de las ciencias de la naturaleza solo es capaz de proporcionar leyes probabilísticas, a fortiori las regularidades de las llamadas ciencias sociales y de la experiencia común - las llamadas "máximas de experiencia" - tendrán también naturaleza probabilística». (GASCÓN ABELLÁN, M., Los hechos en el derecho..., ob. cit., p. 23). En este mismo sentido, sostiene Bunge que si el causalismo de Newton fuese verdadero, «el "azar" no sería más que un sinónimo de "ignorancia de las causas", de modo que un ser omnisciente podría prescindir de esa palabra. Pero las leyes básicas de la física cuántica y de la genética de poblaciones son probabilistas y no se deducen de leyes causales». (BUNGE, M., Evaluando filosofía, Gedisa, Barcelona, 2012, p. 159).

36 En relación con los grados de seguridad, afirma González Lagier que «al igual que podemos distinguir diferentes grados de certeza en las conclusiones de las inferencias probatorias, así también las conclusiones de los razonamientos científicos pueden ser más o menos fiables. De manera que tampoco el carácter probabilístico de la "verdad procesal" es exclusivo de ella. En definitiva, la "verdad procesal" y la "verdad empírica" a) no se diferencian en cuanto a la característica que predican de los enunciados de los que se dice que son verdaderos; b) tampoco en los criterios de verdad; c) solo como cuestión de grado respecto a las restricciones a los medios de averiguación de la verdad; y d) tampoco se diferencian (de nuevo salvo, quizás, como cuestión de grado) en su carácter probabilístico». (GONZÁLEZ LAGIER, D., Hechos y argumentos (racionalidad epistemológica y prueba de los hechos en el proceso penal), Jueces para la democracia, núm. 46, 2003, p. 50).

37 Sobre la probabilidad de la prueba jurídica afirma Ferrer Beltrán que lo único que se deriva de la nota de incertidumbre que caracteriza la toma de decisiones en este ámbito es «una relativización de la confirmación del valor de verdad que podemos atribuir a las conclusiones que alcanzamos en ese ámbito». (FERRER BELTRÁN, J., La valoración racional de la prueba, Marcial Pons, Madrid, 2007, p. 26-27). 
conocimiento científico, han recurrido a la teoría matemática de la probabilidad $^{38}$. Por ello, en la actualidad, por inferencia lógica no se entiende ya aquella lógica que establece reglas para concluir en un enunciado o ley universal a partir de enunciados singulares de observación, sino aquella teoría lógica que se ocupa de averiguar el grado de confirmación, de soporte o apoyo evidencial que tiene una hipótesis en relación con una prueba ${ }^{39}$.

Estas teorías son las que han motivado la propuesta del uso de la estadística en sede judicial para valorar pruebas judiciales, y poder calcular matemáticamente la probabilidad de que el hecho que se afirma pueda tomarse como cierto ${ }^{40}$. Pero, la aparición de la criminalística

38 El concepto matemático de probabilidad, según Gascón Abellán, «concibe a ésta como una propiedad de los sucesos y la interpreta en términos de frecuencia relativa, utilizando para su análisis los métodos estadísticos desarrollados por la matemática». Señala la autora que se trata de un concepto relativamente nuevo que ha experimentado, sin embargo, un extraordinario desarrollo que comenzó con Pascal y Fermat, y continuó con Laplace y Gauss. (GASCÓN ABELLÁN, M., Los Hechos en el Derecho..., ob. cit., p. 24). La idea de una lógica inductiva probabilística, sostiene Aísa Moreu, va asociada «al derrumbamiento del empirismo clásico, según el cual todo el conocimiento debía descansar sobre enunciados observacionales». Más adelante, afirma la autora, con cita de Lakatos y Carnap, que «si no se puede tener conocimiento sobre la verdad o falsedad de las teorías, sí al menos tendremos conocimiento falible, conjetural y probabilístico de ellas». (AÍSA MOREU, D., El razonamiento inductivo en la ciencia y en la prueba judicial, Universidad de Zaragoza, Zaragoza, 1997, p. 21-22).

Según esta Gascón Abellán, Lucena Molina, González, Rodríguez, posibilidad nos conduce al paradigma de la verosimilitud, pues los datos obtenidos mediante métodos probabilísticos han de expresarse estadísticamente en términos de verosimilitud y no de forma categórica. Sobre este paradigma vid. GASCÓN ABELLÁN, M., LUCENA MOLINA, J. J., GONZÁLEZ RODRÍGUEZ, J., Razones científico-jurídicas para valorar la prueba científica; una argumentación multidisciplinar, en Diario La Ley, núm. 7481, Sección Doctrina, octubre, 2010. La verosimilitud no es un concepto ajeno al Derecho. Pues antes del impulso del uso de la estadística en sede judicial se viene manejando en lo que se refiere a la valoración de la prueba. Sobre el mismo y su utilización en la valoración probatoria, señalaba GUTIÉRREZ ALVIZ Y CONRADI que, «la verosimilitud o mejor dicho el juicio de verosimilitud en los casos en que el derecho procesal lo considera relevante, es un juicio que se emite no sobre el hecho sino sobre la afirmación del hecho, es decir sobre la alegación del hecho, y que además se afirma como históricamente ya ocurrido. Verosimilitud y certeza se predican de un juicio en momentos distintos y sucesivos 
en el proceso, y muy especialmente, de aquellas pruebas forenses que acompañan sus conclusiones de un porcentaje de certeza, ha enfatizado este paralelismo entre el probabilismo jurídico y el matemático, lo que, como veremos en lo que sigue, en ocasiones ha provocado más confusiones que certezas.

\subsection{LA TEORÍA DE LA PROBABILIDAD BAYESIANA}

En el amplísimo y complicado debate suscitado por el carácter probabilístico de la prueba, resulta especialmente relevante el cálculo de probabilidades cuantitativas mediante el teorema de Bayes ${ }^{41}$. Sin ánimo de extendernos demasiado en este cálculo matemático, pues no es propio de un trabajo jurídico, cabe mencionar siquiera cuál es la base del razonamiento de dicho teorema, para poder ponerla en relación con la valoración probatoria. Pues bien, el teorema de Bayes puede ser definido como «una consecuencia inmediata de la ley de multiplicación que sirve para conocer las probabilidades finales de un suceso a partir de las probabilidades iniciales, dada cierta información o informaciones adicionales obtenidas ${ }^{42}$. De este modo, el método proporciona una forma adecuada de incorporar información previa de un suceso además de permitir incorporar información posterior cuando ésta sea accesible.

y no cabe o no se debe por ello confundirlos». (GUTIÉRREZ ALVIZ Y CONRADI, F., La valoración de la prueba penal, en AA.VV., Escritos en homenaje al profesor Prieto-Castro, Editorial Nacional, Madrid, vol. II, 1979, p. 113).

${ }^{41}$ El Teorema de Bayes fue diseñado por el matemático británico Thomas Bayes, al estudiar el problema de la determinación de las causas a través de los efectos observados. En su obra Essay Towards Solving a Problem in the Doctrine of Chances, de 1763, se utilizaba por primera vez la probabilidad inductivamente, y se establecía una base matemática para la inferencia probabilística. De este modo, la fórmula de Bayes permite calcular las probabilidades a posteriori, siempre y cuando conozcamos las probabilidades a priori y las verosimilitudes. Sobre el uso de este teorema en el razonamiento probatorio vid., especialmente, TILLERS, P., GREEN, E., Probability and Inference in the Law of Evidence: the uses and limits of Bayesianism, Kluwer, Dordrecht, The Netherlands, 1988.

${ }^{42}$ VARGAS ÁVILA, R., La valoración de la prueba científica de ADN en el proceso penal, Prolegómenos. Derechos y valores, núm. 25, 2010, p. 143. 
En su formulación más simple, el teorema de Bayes mide, mediante el likelihood ratio (LR), cuántas veces es más probable el suceso de culpabilidad que el de inocencia, en función de unos parámetros dados:

Likelihood Ratio $=\frac{\text { probabilidad del hallazgo científico dada la culpabilidad }}{\text { probabilidad del hallazgo científ ico dada la inocencia }}$

Por ejemplo, si tenemos una huella dactilar de doce puntos característicos que coinciden con los del acusado, el numerador de este ratio supondrá que tal huella pertenece al encausado, por lo que valdrá 1 , mientras que el denominador ha de reflejar la frecuencia con la que las características de estos doce puntos aparecen en el resto de la población ${ }^{43}$. Supongamos que estas marcas lofoscópicas aparecen en 7 de cada 100 personas. Por tanto, el denominador del cociente LR valdrá 0,07 y, consecuentemente, el LR tendrá un valor de 14,28 $(\mathrm{LR}=1 / 0,07)$. Este resultado nos viene a decir que es 14,28 veces más probable que la huella dactilar pertenezca al encausado si suponemos que esa huella la dejó él, que si suponemos que la dejó otra persona ${ }^{44}$. Cuando el resultado del LR es igual a 1, la evidencia es neutra, es decir, apoya por igual la hipótesis de

${ }^{43}$ Esto es lo que se conoce en estadística como probabilidades condicionadas, es decir, tenemos un valor de la huella dactilar condicionado a que el encausado sea el culpable (que vale 1) y otro valor de esa misma huella condicionado a que el encausado sea inocente (en este caso, 0,07).

44 En este sentido, es esencial una correcta lectura de los resultados obtenidos pues, de lo contrario, cambiaría por completo el significado de las conclusiones de los protocolos criminalísticos. Por ello, insisten GASCÓN ABELLÁN, LUCENA MOLINA Y GONZÁLEZ RODRÍGUEZ en que «en este sentido, lo único que el perito puede (y debe) hacer es expresar los resultados de la prueba de un modo científicamente riguroso y que al mismo tiempo permita al juez comprender el alcance exacto de los mismos de cara a realizar su valoración ponderándolos con el resto de pruebas. Por eso, en pro del rigor pero también de la claridad, el perito debería huir en su informe de las expresiones categóricas o probabilísticas sobre las hipótesis planteadas por las partes con respecto a un cotejo criminalístico y optar en cambio por pronunciamientos del tipo: «es $R$ veces más probable que coincidan los perfiles genéticos si el vestigio $x$ procede de $f$ que si no procede de $f$ »; o «es $R$ veces más probable que coincidan las huellas dactilares si la huella es del acusado que si no lo es»»». (GASCÓN ABELLÁN, M., LUCENA MOLINA, J. J., GONZÁLEZ RODRÍGUEZ, J., Razones científico-jurídicas para valorar a prueba científica..., ob. cit., p. 9). 
culpabilidad que la de inocencia. Y, finalmente, cuando el LR es menor que 1, la evidencia apoya la hipótesis de inocencia. De este modo, por medio del LR, podemos hacernos una idea del significado de una prueba estadística.

Un paso más en este teorema, nos permite combinar los resultados de la probabilidad que arroja la prueba estadística con el valor probatorio de otras pruebas no estadísticas. El resultado de esta combinación se denomina «probabilidad a posteriori» y se obtiene multiplicando el LR por la «probabilidad a priori» ${ }^{45}$. Para calcular la «probabilidad a priori» el juez tiene que evaluar la información proporcionada por el resto de las pruebas practicadas en el plenario y asignarle un valor numérico. De esta manera, el teorema de Bayes mide el impacto que, sobre la probabilidad subjetiva previa del hecho que se pretende acreditar, provoca la toma en consideración de la prueba estadística ${ }^{46}$. Su utilidad procesal, por tanto, consiste en ser un instrumento que permite combinar información estadística sobre un suceso, con información que carece de esa naturaleza, proporcionando una valoración final agregada de la probabilidad del suceso. Esto es, siguiendo con el ejemplo propuesto, tomando como LR 14,28 , el resultado de la prueba estadística incrementaría la probabilidad a posteriori. Y esto sucedería con más intensidad mientras más pruebas acrediten la culpabilidad. Por el contrario, la probabilidad a posteriori se vería menos incrementada por la prueba estadística si la probabilidad a priori es baja, por apuntar el resto del material probatorio a la inocencia del encausado, y pese a lo elevado del LR.

En virtud de este razonamiento, según Vargas Ávila, «la aportación del teorema bayesiano permite restablecer el principio de libre valoración

45 La formulación es sumamente simple, pues consiste una sencilla multiplicación: $\mathrm{P}$ a posteriori $=\mathrm{LR} \times \mathrm{P}$ a priori.

46 Como recoge Ferrer Beltrán, los defensores del teorema de Bayes, sostienen que cualquier inferencia probatoria, y no solo las que se realizan respecto de la prueba estadística, «se basa sustancialmente en la aplicación del teorema de Bayes bajo la interpretación subjetivista de la probabilidad como grado de creencia racional. Así, lo que el método de cálculo nos dice es qué grado de creencias es racional tener en la hipótesis dado un elemento de juicio si antes de conocer el elemento de juicio teníamos un grado de creencia $\mathrm{x}$ en ella $\mathrm{y}$ dadas las probabilidades inversas de que esté presente el elemento de juicio si la hipótesis es verdadera y si no lo es». (FERRER BELTRÁN, J., La valoración racional de la prueba, ob. cit., p. 110). 
de la prueba en toda su extensión cuando parecía que, precisamente, la aplicación de los métodos científicos reducía la capacidad judicial de apreciar críticamente los resultados probatorios ${ }^{47}$. No obstante, no debe soslayarse que, como veremos a continuación, la aplicación de este teorema presenta diversos problemas en la valoración judicial. Por un lado, el hecho de atribuir probabilidades numéricas a una prueba que no presenta sus resultados estadísticamente, como puede ser una testifical, y mezclarlo con otra prueba que sí lo hace, como puede ser una de ADN, dispara la complejidad de estos cálculos matemáticos y, con ella, la facilidad de incurrir en equívocos, tanto procedimentales como interpretativos ${ }^{48}$. Por otro lado, la población que se tome como referencia para el cálculo de las probabilidades es crucial, por lo que puede alterar sustancialmente el resultado.

\subsection{LA APLICACIÓN DE LA ESTADÍSTICA AL ÁMBITO PROBATORIO}

Acaba de exponerse como, mediante la inferencia bayesina, desde el punto de vista matemático se puede demostrar que con el cálculo de probabilidades es posible representar de modo numérico un conjunto racional de creencias, de manera que se establezca una relación entre probabilidad e información. Más aún, como hemos visto, la regla de Bayes proporciona una vía de actualización de las creencias cuando aparece nueva información, con la sencilla modificación del valor atribuido a la probabilidad a priori. Sin embargo, de esto no se sigue necesariamente que el cálculo de probabilidades pueda esclarecer la fuerza probatoria que juegan las pruebas estadísticas en el contexto de un cuerpo probatorio

47 VARGAS ÁVILA, R., «La valoración de la prueba...», ob. cit., p. 143.

48 En este sentido, señala Gascón Abellán que, «la fórmula bayesiana supone un cálculo matemático relativamente simple en el caso-base de tener que valorar una sola prueba que versa directamente sobre la hipótesis a probar, que es además una hipótesis simple, pero la complicación del cálculo aumenta de manera impresionante, al punto de producir "indigestión intelectual”, cuando se usa para resolver situaciones más complejas, como la pluralidad de elementos de prueba relativos a la misma hipótesis, la cascaded inference o la prueba de una hipótesis referente a un hecho complejo». (GASCÓN ABELLÁN, M., Los hechos en el derecho..., ob. cit., p. 149). 
más extenso ${ }^{49}$. Por el contrario, se corre el riesgo de que nos encontremos con la situación opuesta, pues el probabilismo jurídico nos incita a confundir las probabilidades estadísticas con el valor de la prueba, y ello puede tentarnos a caer en equívocos, como formular e interpretar los resultados obtenidos según la opción que más convenga a cada parte, $\mathrm{u}$ olvidar que las pruebas estadísticas de un caso deben valorarse junto con otras muchas que no ofrecen resultados estadísticos.

En este sentido, una errónea interpretación del resultado estadístico en la valoración de una prueba puede conducir a lo que, doctrinalmente, se ha llamado la falacia del fiscal y la falacia de la defensa ${ }^{50}$. Esta interpretación, en la mayoría de los casos, se debe a una presentación sesgada de los resultados estadísticos por el experto de cada parte ${ }^{51}$. Y es

49 Como señala Haack, «no hay duda alguna de que las pruebas estadísticas desde los análisis de ADN en casos penales hasta los estudios epidemiológicos en casos de daños por sustancias tóxicas y los cálculos actuariales en demandas de daños por muerte, etc.- juegan un papel muy significativo en el derecho; y de forma totalmente apropiada. Y tampoco hay duda de que el cálculo matemático de probabilidades sea aplicable a las pruebas estadísticas. [...] Pero los cálculos de probabilidad de una coincidencia con el demandado son extrapolaciones matemáticas de los datos empíricos. No son datos matemáticos puros; pero tampoco son exactamente estadísticos, pudieran ser cualquiera de los dos si esto se interpreta como basados en estudios de patrones de una muestra en la población». (HAACK, S., El probabilismo jurídico: una disensión epistemológica, en VÁZQUEZ ROJAS, C., Estándares de prueba y prueba científica, Marcial Pons, Madrid, 2013, p. 89 y ss).

50 Esta denominación apareció por vez primera en el artículo estadounidense: THOMPSON, E. L., SHUMANN, E. L., Interpretation of Statistical Evidence in Criminal Trials: The Prosecutor's Fallacy and the Defense Attorney's Fallacy, in Law and Human Behavior, Springer, vol. II, n. 3, 1987. En España se ha realizado una traducción literal de esta expresión, pero debe reseñarse que esta denominación no responde al funcionamiento del proceso penal español. Mientras que en EEUU el fiscal en juicio oral siempre acusa, en España, como es sabido, aunque esto suceda en la mayoría de los casos puede no ocurrir. Por tanto, creemos más acertada que estas falacias hubieran sido traducidas como «la falacia de la acusación» y «la falacia de la defensa», para evitar equívocos en la función del Ministerio Fiscal.

51 Desde una perspectiva racionalista para el ejercicio de un derecho estadístico, es fundamental distinguir bien entre el cálculo y el análisis estadístico, o, como señala Torres Manrique, «entre la descripción y la heurística (búsqueda de datos relevantes para un propósito concreto)». Continua el autor afirmando que «otro concepto fundamental para la filosofía de la estadística, y por lo tanto, para cualquier perspectiva jurídica, es el de la interpretación 
que, cuando lo que el proceso desea conocer es la probabilidad de que una huella dactilar o una muestra de ADN provenga del encausado, para responder a esta incógnita cada experto podrá expresar los resultados obtenidos de una misma prueba forense de diversa forma. Veamos mejor con un ejemplo cómo podrían darse estas interpretaciones engañosas.

Por continuar con el ejemplo anterior, si la huella dactilar obtenida se analiza según el sistema electrónico SAID y se concluye que esas marcas dactilares solo la poseen dos de cada cien personas, la acusación presentaría el caso afirmando que: «Las marcas analizadas la posee solo el $2 \%$ de la población, por lo que solo hay un $2 \%$ de probabilidades de que esa huella provenga de otro individuo. Ello significa que la probabilidad de que el acusado sea culpable es de un 98\%». De otra parte, la defensa sostendría que: «En una población como Barcelona, con más de un millón y medio de habitantes, el $2 \%$ de la población equivale a más de 30.000 personas. Por consiguiente, la probabilidad de que el acusado sea culpable es una entre 30.000». Según sostiene Carracedo Álvarez, ninguno de estos argumentos es correcto, pues no podemos pasar por alto que el teorema de Bayes se basa en probabilidades condicionadas, por lo que nos ofrece un resultado sobre la base de una hipótesis ${ }^{52}$. Esto es, no concluye que el encausado sea culpable, sino que es $\mathrm{X}$ veces más probable que sea culpable si sostenemos la hipótesis de culpabilidad. En el ejemplo anterior la hipótesis ha sido de culpabilidad, pues considerando

o hermenéutica. Las habrá mejores y peores, correctas e incorrectas; pero no dejan de ser interpretaciones más o menos discutibles muchas de las aplicaciones estadísticas, sometidas por lo tanto a las reglas de la hermenéutica tanto como puedan estarlo los comentarios de textos legales y la interpretación casuística de jurisprudencia y doctrina». (TORRES MANRIQUE, J. I., Reflexiones acerca del advenimiento del nada lejano, como aparentemente inortodoxo y eventualmente infuturible, escenario de un derecho estadístico, Derecho y Cambio Social, 2011, p. 11).

52 Tras negar la veracidad de estos argumentos, el autor afirma que «el problema es que tanto con las imágenes, como con las palabras y mucho más con las probabilidades, no puede confiarse, en ocasiones, totalmente de la intuición y experiencia, pues es fácil que se produzca paradojas lógicas. Es necesario aprender un método para poder realizar una valoración correcta». (CARRACEDO ÁLVAREZ, A., Valoración de la prueba del ADN, en MARTÍNEZ JARRETA, M. B., La prueba del ADN en medicina forense: la genética al servicio de la ley, Masson, Bacelona, 1999, p. 303). 
que el encausado cometió el delito -denominador al que atribuimos el valor $1-$, llegamos a la conclusión de que es 14,28 veces más probable que la huella dactilar pertenezca al mismo, que si considerásemos que no lo ha hecho él. Por lo que todo lo que se multiplique a ese cociente, estará determinado por la hipótesis de culpabilidad, que será lo que interese, en este caso, a la acusación. Quizás, lo más acertado para no incurrir en engaños interpretativos sería presentar varios cálculos, es decir, calcular la probabilidad del hallazgo científico dada la culpabilidad y dada la inocencia, para que el juez pueda valorar con base en resultados objetivos ${ }^{53}$.

Ahora bien, no solo presentan estos problemas las pruebas derivadas de la criminalística. El uso de la estadística en los resultados probatorios es una práctica que, dada su proliferación, es utilizada para argumentar posiciones procesales que se basan en pruebas de otra naturaleza. En relación con ello, debe destacarse el caso británico de Sally Clark. Sally Clark dio a luz a un bebé el 26 de septiembre de 1996. El 13 de diciembre de ese mismo año Clark llamó alarmada a una ambulancia al ver a su bebé inconsciente poco después de haberlo acostado. Una vez en el hospital fue declarado muerto por los médicos que lo atendieron. Poco más tarde, el 29 de noviembre de 1997 nació otro hijo del matrimonio que con tan solo ocho semanas de vida fue hallado muerto en su casa. Sally Clark había estado sola ante ambos fallecimientos y ello hizo que fuera acusada de infanticidio. Por un lado, la defensa argumentó que se trataba de dos casos de «muerte súbita del lactante», un fenómeno sin causa conocida que afecta a uno de cada 8.500 recién nacidos.

Por otro lado, el testimonio del experto que aportó la fiscalía logró demostrar, según la acusación científicamente pero, realmente estadísticamente, que esos fallecimientos fueron provocados. Para este pediatra la explicación era sencilla: si la muerte súbita de un bebé acontece una de

53 Así lo sugieren, Carracedo Álvarez y Vargas Ávila. El primero de estos autores considera que «es de sentido común adoptar una postura equidistante entre la dicotomía fisca/defensa. Hay que reconocer que existen ambos puntos de vista, y que la posición justa está en contemplarlos ambos». (CARRACEDO ÁLVAREZ, A., Valoración de la prueba de ADN, ob. cit., p. 305). Por su parte, Vargas Ávila sugiere que «el perito presente no uno, sino varios cálculos posibles de probabilidad en los que se reflejen diversos valores apriorísticos para que el tribunal atendiendo al valor incriminatorio o exculpatorio se decida por uno de ellos». (VARGAS ÁVILA, R., La valoración de la prueba científica de ADN, ob. cit., p. 144). 
cada 8.500 veces, la muerte súbita de dos ocurre una de cada setenta y tres millones de veces $-8.500^{2}$, algo así como 1 entre 73 millones-. Con lo que, este dato, sumado al hecho de que la única persona que había en la casa en el momento del fallecimiento era Sally Clark llevó al jurado -con ocho votos a favor frente a dos en contra- a declararla culpable de los asesinatos de sus dos hijos, y al juez a imponerle la pena de cadena perpetua. Tras la condena, la Royal Statistical Society -una de las sociedades más distinguidas y célebres a nivel mundial en el ámbito de la estadística- elaboró y entregó un informe explicando el mal uso que se había practicado de la estadística en los tribunales para la resolución de esta contienda. En el informe la Royal Statistical Society argumentó que el hecho de que la probabilidad de muerte súbita del primer hermano sea de una entre 8500 no significa que la de los dos sea una entre $8500^{2}$, porque las probabilidades sólo se multiplican si los sucesos son independientes. Además, apunta el informe que, los casos que manejó el pediatra de la acusación no detallaban si había más incidencia de muertes súbitas en familias en las que ya había habido alguna. Y, sin embargo, es casi obvio pensar que puede haber tal correlación. Dicho informe, junto con otras pruebas médicas recopiladas por la defensa, absolvieron a Clark tres años y medio después de estar cumpliendo condena $^{54}$. Por lo que, este caso real evidencia la advertencia que vinimos realizando, y es que: la probabilidad de dos muertes súbitas en una familia, no era el equivalente a la probabilidad de que Sally fuera culpable.

Por último, otra de las imprecisiones a considerar, es la relacionada con la población de referencia, ya que cualquier probabilidad de este tipo está formulada sobre la base de una muestra, tomada de una población en concreto $^{55}$. Por ejemplo, en la investigación de un asesinato cometido en

54 Para profundizar sobre este caso, vid., ad exemplum, CHILLEY, J., Expert evidence and miscarriage of justice. The case of Sally Clark, Grin, 2015. Otro caso paradigmático en el uso erróneo de la estadística para fundamentar una condena es el conocido como «el pueblo contra Collins». En ROHATGI, V., Statistical Inference, Dover Publications, New York, 2003, p. 65 y ss., se explica con detalle este caso en términos probabilísticos.

55 El resultado de la prueba puede considerarse absolutamente cierto cuando excluye la identidad de las dos muestras, la dubitada y la indubitada; pero cuando afirma la identidad surgen dudas, pues este resultado depende de un complejo cálculo estadístico: la probabilidad de la identidad depende de la población de referencia, y puede suceder que no esté claro cuál haya de ser esa población 
Barcelona, no tendría por qué considerarse a la población de toda la ciudad, pues tal vez, según las pesquisas del caso, el círculo de sospechosos sea más reducido, y baste incluso con seleccionar la población del distrito donde vivía o donde trabajaba la víctima. Con la finalidad de afinar en lo que se refiere a la población de muestra, podría ser una solución que el juez sea el que la determine, ya que es él quien conoce en profundidad las circunstancias particulares del delito, y no el experto al que se pide que practique la prueba.

\section{Consideraciones finAles}

La complejidad de las inferencias del razonamiento jurídico ha llevado a la inclusión en el proceso de cálculos estadísticos con la pretensión de que la valoración de ciertas pruebas sea lo más objetiva posible. Sin embargo, ni las partes ni los jueces parecen tener un dominio adecuado de estas herramientas matemáticas $\mathrm{y}$, menos aún, de cómo aplicarlas en el ámbito judicial. Además, como hemos señalado supra, no todas las pruebas pueden presentar sus resultados en forma de porcentajes probabilísticos, por lo que habría que atribuirles un valor numérico con base en criterios lógicos o del raciocinio inferencial, lo que, pese a no ser aleatorio, tampoco parece muy riguroso.

En relación con ello, ya hemos visto que el teorema de Bayes incluye las probabilidades asociadas a las pruebas no estadísticas mediante lo que hemos denominado la «probabilidad a priori». La cuestión es ¿cómo se determina esta probabilidad? Insistimos en que, asignar números precisos a la convicción judicial sobre la certeza que proporcionan las

- sobre todo en sociedades multiétnicas - o que no se disponga de datos suficientes sobre los vestigios analizados. (TARUFFO, M., Le prove scientifiche nella recente esperienza statunitense, Revista Vasca de Derecho Procesal y Arbitraje, vol. 8, núm. 2, 1996, p. 214 y ss). En esta misma línea, sostiene Carracedo Álvarez que: «Normalmente, el perito escoge la población del entorno del caso, lo que habitualmente coincide con un grupo poblacional concreto. Por ejemplo, si el caso es de Galicia se utiliza la población gallega residente, o si es en Cataluña, la población catalana residente. Aunque utilizar este tipo de población es habitualmente lo más apropiado, no existen, en general, diferencias importantes si se utilizan datos globales de población española, aunque sí puede haberlo si se utilizan erróneamente por el perito datos de poblaciones autóctonas particulares y no de población residente». (CARRACEDO ÁLVAREZ, A., Valoración de la prueba de ADN, ob. cit., p. 306). 
pruebas que se presentan en sala supondría determinar probabilidades matemáticas en función de creencias subjetivas que, aunque estén regidas por la sana crítica, no son directamente identificables, objetivamente, con una cifra concreta. Y es que la probabilidad a priori no viene dada por una cifra predeterminada, sino que hace referencia al concepto de probabilidad lógica del que hablábamos al principio de este artículo, cuyo cálculo requiere cohonestar todas las premisas singulares para, a través del razonamiento inductivo, poder alcanzar una conclusión general.

En principio, ante la ausencia de premisas singulares, podría atribuírsele a la probabilidad a priori el valor del $50 \%$, pues a falta de otros indicios o pruebas hay las mismas posibilidades de culpabilidad que de inocencia. Ahora bien, a medida que se van obteniendo más datos e informaciones sobre lo sucedido, la probabilidad a priori se irá modificando, y se sustituirá el 50\% por una cifra progresivamente más elevada, si es que se incrementan los indicios o pruebas inculpatorias, o por una probabilidad inferior en caso de que disminuyan dichos indicios ${ }^{56}$. Siendo así, se presenta un importante problema de inadecuación de la probabilidad bayesiana para valorar las pruebas estadísticas junto con las no estadísticas en un caso concreto. Pues, si la probabilidad a priori es distinta entre los juzgadores de un caso, entonces la probabilidad a posteriori, conformada por la multiplicación de las probabi-

56 Sobre la utilización de estos elementos como factores a tener en cuenta para confirmación de la solidez de una alegación, sostiene Gascón Abellán que «el grado de confirmación de una hipótesis, aumenta o disminuye en función de los siguientes elementos: el fundamento cognoscitivo de las leyes causales que conectan las pruebas con la hipótesis (no es lo mismo que esas leyes causales gocen de un sólido fundamento científico, que sean genéricas e imprecisas máximas de experiencia, o que reproduzcan simples tópicos o prejuicios difundidos); la solidez epistemológica (o el grado de certeza) de las pruebas que la confirman (no es lo mismo que la hipótesis venga confirmada por el resultado de una prueba de ADN o por un testimonio no demasiado sólido); el número de pasos inferenciales que separan las pruebas de la hipótesis (no es lo mismo que la hipótesis venga confirmada por una prueba directa o por una prueba circunstancial); la cantidad de pruebas o confirmaciones (no es lo mismo que la hipótesis venga confirmada por una sola prueba, por algunas pruebas o por muchas pruebas); y la variedad de pruebas o confirmaciones, pues la variedad de pruebas proporciona una imagen más completa de los hechos (no es lo mismo que la hipótesis venga confirmada solo por testimonios directos o que venga confirmada por testimonios directos, pruebas científicas y pruebas indiciarias)». (GASCÓN ABELLÁN, M., Sobre la posibilidad de formular estándares de prueba objetivos, Jueces para la democracia, núm. 54, 2005, p. 86). 
lidades entre pruebas estadísticas y no estadísticas, también lo será. Con lo que, podemos encontrarnos que dos jueces distintos arriben a conclusiones diferentes a partir de los mismos datos. Se comprueba así, cómo el uso de las inferencias bayesianas no ofrece exactitud en la valoración de las pruebas, sino una mera aproximación expresada con una fórmula matemática que, en última instancia, opera sobre la base del mismo razonamiento que emplea el sistema de libre valoración de las pruebas: mediante la confirmación de hipótesis según los medios probatorios practicados.

Si a ello le unimos las interpretaciones de parte que, consciente o inconscientemente, suelen contener sesgos que proporcionan mayor carga probatoria a sus alegaciones, llegamos a la conclusión de que el uso de la probabilidad y la estadística como herramientas para la valoración jurídico-probatoria siembra más dudas que certezas. Lo aconsejable es continuar empleando el criterio de la sana crítica y las máximas de experiencia para valorar tanto pruebas que ofrecen sus resultados con cifras estadísticas como aquellas que no lo hacen ${ }^{57}$. De este modo, se evitará

57 Dado que los términos "sana crítica” y "máximas de experiencia” no son utilizados por todos los ordenamientos jurídicos y que, entre los que lo utilizan no son plenamente coincidentes, cabe aclarar qué sentido encuentran en el caso español. En acertadas palabras de Garciandía, puede entenderse a la sana crítica como «principios, axiomas, máximas, directrices, razones que deben servir de medida, de canon al que se han de ajustar las acciones, los juicios y las opiniones para que resulten rectas [...], las reglas de la sana crítica constituyen "el único módulo de control judicial" que existe, o lo que es lo mismo, "las reglas ponderativas", “cánones amplísimos” por definición, que permiten fiscalizar los criterios aplicables o modos empleados por el juzgador en la valoración». (GARCIANDÍA GONZÁLEZ, P., La peritación como medio de prueba en el proceso civil español, Aranzadi, Pamplona, 1999, p. 266-267). De modo más breve, según Couture, la «sana crítica» constituye un sistema de valoración de la prueba caracterizado fundamentalmente por dos elementos esenciales: se trata de reglas que aluden al correcto entendimiento humano, y se trata de reglas construidas a partir de la lógica y la experiencia común llamadas a imponer finalmente la racionalidad y razonabilidad del juicio. (COUTURE, E., Fundamentos de Derecho Procesal Civil, Fundamentos del Derecho Procesal Civil, Depalma, Buenos Aires, 1986, p. 270 y ss). En esta misma línea Font Serra expresa que las reglas de la sana crítica son una combinación de los criterios lógicos y de las máximas de experiencia que debe utilizar el juez para apreciar la prueba. (FONT SERRA, E., «El dictamen de peritos en la nueva Ley de Enjuiciamiento Civil», en La Prueba, Cuadernos de derecho judicial, CGPJ, Madrid, 2000, p. 104 y ss). Por tanto, puede afirmarse que las reglas de la sana crítica se concretan básicamente en dos criterios directores del razonamiento judicial: 
confiar en datos numéricos que para nada solucionan el entresijo que supone acreditar el acaecimiento de unos hechos.

\section{RefERENCIAS BIBLIOGRÁFICAS}

AÍSA MOREU, D., El razonamiento inductivo en la ciencia y en la prueba judicial, Universidad de Zaragoza, Zaragoza, 1997.

ALCHOURRÓN, C., BULYGIN, E., Los límites de la lógica y el razonamiento jurídico, en Análisis lógico y derecho, Centro de Estudios Constitucionales, Madrid, 1991.

BUNGE, M., La ciencia: su método y su filosofía, Debolsillo, 2009.

BUNGE, M., Evaluando filosofía, Gedisa, Barcelona, 2012.

CALAMANDREI, P., Il giudice e lo storico, trad. SENTÍS MELENDO, en Estudios sobre el proceso civil, Buenos Aires, 1945.

CALAMANDREI, P., La genesi lógica della giustizia civile, Opere giuridiche, Morano, Napoli, 1965.

CALVO GONZÁLEZ, J., Verdades difíciles, control judicial de hechos y juicio de verosimilitud, Cuadernos electrónicos de filosofía del derecho, núm. 15, 2007.

la lógica, de un lado, y la experiencia común del juzgador, de otro. Si la lógica impone un determinado modo de conducir el razonamiento a partir de premisas encadenadas sobre la base de principios que permiten la deducción argumental sucesiva, las máximas de experiencia sirven como control interno tanto de razonabilidad de las deducciones lógicas como de la aceptabilidad de los resultados a que ellas conducen. Un profundo estudio sobre las máximas de experiencia puede encontrar en la obra de STEIN, F., El conocimiento privado del juez, trad. DE LA OLIVA, A., Centro de Estudios Ramón Areces, Madrid, 1990. En este famoso trabajo sobre la ciencia privada del juez se concluyó que el juez en determinadas situaciones puede servirse de su propio saber extraprocesal y extrajurídico. Sus argumentos fundamentales son, que junto a los tradicionales elementos lógicos que sirven al juez para construir la sentencia - las normas y los hechos concretos- es preciso añadir las máximas de experiencia (Erfahrungssätze) que no pertenecen ni a uno ni a otro, constituyendo una tercera categoría, en cuanto se trata de definiciones o juicios hipotéticos de contenido general independientes del caso concreto y de sus circunstancias, adquiridos por la experiencia pero autónomos respecto a los casos particulares de cuya observación se deducen. En definitiva, la suma del silogismo lógico-argumental, sometido a la crítica de la experiencia común del juez, constituyen la base de la sana crítica, y el punto de anclaje de variados criterios - prudente apreciación, sentido común, conciencia, raciocinio humano, buen criterio, corrección del resultado deductivo, etc. - que han venido a enriquecer un sistema de valoración de la prueba cuya principal virtualidad es encauzar dentro de la razón la libertad del juzgador en la apreciación de los distintos medios probatorios. 
CAPRIOLI, F., Verità e giustificazione nel processo penale, Revista Brasileira de Direito Processual Penal, Porto Alegre, vol. 3, n. 1, 2017. https://doi.org/10.22197/ rbdpp.v3i1.30

CARNELUTTI, F., La prueba civil, trad. ALCALÁ-ZAMORA Y CASTILLO, Depalma, Buenos Aires, 1982.

CARRACEDO ÁLVAREZ, A., Valoración de la prueba del ADN, en MARTÍNEZ JARRETA, M. B., La prueba del ADN en medicina forense: la genética al servicio de la ley, Masson, Bacelona, 1999.

CHILLEY, J., Expert evidence and miscarriage of justice. The case of Sally Clark, Grin, 2015.

COHEN, L. J., The probable and the provable, Clarendon Press, Oxford, 1977. https://doi.org/10.1093/acprof:oso/9780198244127.001.0001

ESPEJO MIRANDA, I., Estadística descriptiva y probabilidad, Servicio de Publicaciones de la Universidad de Cádiz, Cádiz, 2006.

COUTURE, E., Fundamentos de Derecho Procesal Civil, Fundamentos del Derecho Procesal Civil, Depalma, Buenos Aires, 1986.

FERRAJOLI, L., Derecho y razón: teoría del garantismo penal, Trotta, Madrid, 1989. FERRER BELTRÁN, J., Prueba y verdad en el derecho, Marcial Pons, Madrid, 2005. FERRER BELTRÁN, J., La valoración racional de la prueba, Marcial Pons, Madrid, 2007.

FONT SERRA, E., El dictamen de peritos en la nueva Ley de Enjuiciamiento Civil, en La Prueba, Cuadernos de derecho judicial, CGPJ, Madrid, 2000.

FROSINI, B., Le prove statistiche nel proceso penale e nel processo civile, Giuffrè, Milano, 2002.

GARCIANDÍA GONZÁLEZ, P., La peritación como medio de prueba en el proceso civil español, Aranzadi, Pamplona, 1999.

GASCÓN ABELLÁN, M., Sobre la posibilidad de formular estándares de prueba objetivos, Jueces para la democracia, núm. 54, 2005.

GASCÓN ABELLÁN, M., Los Hechos en el Derecho. Bases argumentales de la prueba, Marcial Pons, Madrid, 2010.

GASCÓN ABELLÁN, M., LUCENA MOLINA, J. J., GONZÁLEZ RODRÍGUEZ, J., Razones científico-jurídicas para valorar la prueba científica; una argumentación multidisciplinar, Diario La Ley, núm. 7481, Sección Doctrina, octubre, 2010.

GONZÁLEZ ECHEVARRÍA, A., La construcción teórica en antropología, Anthropos, Barcelona, 1987. 
GONZÁLEZ ECHEVARRÍA, A., Crítica de la singularidad cultural, Anthropos, Barcelona, 2003.

GONZÁLEZ LAGIER, D., Hechos y argumentos (racionalidad epistemológica y prueba de los hechos en el proceso penal), Jueces para la democracia, núm. 46, 2003. GRAJALES, A., Argumentación jurídica, Astrea, Buenos Aires, 2014.

GUTIÉRREZ ALVIZ Y CONRADI, F., La valoración de la prueba penal, en AA. VV., Escritos en homenaje al profesor Prieto-Castro, Editorial Nacional, Madrid, vol. II, 1979.

HAACK, S., El probabilismo jurídico: una disensión epistemológica, en VÁZQUEZ ROJAS, C., Estándares de prueba y prueba científica, Marcial Pons, Madrid, 2013.

HACKING, I., El surgimiento de la probabilidad, Gedisa, Barcelona, 1995.

LAUDAN, L., Por qué un estándar de prueba subjetivo y ambiguo no es un estándar. Doxa, Cuadernos de Filosofía del Derecho, núm. 28, 2005. https://doi. org/10.14198/doxa2005.28.08

LÓPEZ BARJA DE QUIROGA, J., Instituciones de derecho procesal penal, Mendoza, Cuyo, 2001.

LÓPEZ ORTEGA, J. J., Información y justicia: la dimensión constitucional del principio de publicidad judicial y sus limitaciones, en Justicia y medios de comunicación, Consejo General del Poder Judicial, Madrid, 2007.

LORUSSO, S., La prova scientifica, en GAITO, A., La prova penale, Utet, Torino, 2008.

LUNA SERRANO, A., Acerca de las verdades presuntas que inducen certeza, en Estudios jurídicos en homenaje al profesor Manuel García Amigo, La ley, Madrid, 2015.

MARTÍNEZ SOLANO, J. F., El problema de la verdad en K.R. Popper: reconstrucción histórico-sistemática, Netbiblio, 2005.

RAMÍREZ FIGUEROA, A., Transformación de la Epistemología Contemporánea. De la unidad a la dispersión, Universitaria, 2004.

RIVADULLA RODRÍGUEZ, A., Probabilidad e inferencia científica, Anthropos, Barcelona, 1991.

ROHATGI, V., Statistical Inference, Dover Publications, New York, 2003.

PERELMAN, C., La lógica jurídica y la nueva retórica, Civitas, Madrid, 1988.

STEIN, F., El conocimiento privado del juez, trad. DE LA OLIVA, A., Centro de Estudios Ramón Areces, Madrid, 1990.

TARUFFO, M., Le prove scientifiche nella recente esperienza statunitense, Revista Vasca de Derecho Procesal y Arbitraje, vol. 8, núm. 2, 1996.

TARUFFO, M., Simplemente la verdad, Marcial Pons, Madrid, 2010. 
TARUFFO, M., La prueba de los hechos, Trotta, Madrid, 2011.

THOMPSON, E. L., SHUMANN, E. L., Interpretation of Statistical Evidence in Criminal Trials: The Prosecutor's Fallacy and the Defense Attorney's Fallacy, Law and Human Behavior, Springer, vol. II, n. 3, 1987.

TILLERS, P., GREEN, E., Probability and Inference in the Law of Evidence: the uses and limits of Bayesianism, Kluwer, Dordrecht, The Netherlands, 1988.

TORRES MANRIQUE, J. I., Reflexiones acerca del advenimiento del nada lejano, como aparentemente inortodoxo y eventualmente infuturible, escenario de un derecho estadístico, Derecho y Cambio Social, 2011.

VARGAS ÁVILA, R., La valoración de la prueba científica de ADN en el proceso penal, Prolegómenos. Derechos y valores, núm. 25, 2010. https://doi.org/10.18359/ prole. 2450

WEINSTEIN, J. B., Some Difficulties in Devising Rules for Determining Truth in Judicial Trials, Col. L. Rev. 66, 1966. https://doi.org/10.2307/1120774

WITTGENSTEIN, L., Sobre la certeza, trad. por Isidoro Reguera, Gredos, Madrid, 2009.

\section{Informações adicionais e declarações dos autores (integridade científica)}

Declaração de conflito de interesses (conflict of interest declaration): a autora confirma que não há conflitos de interesse na realização das pesquisas expostas e na redação deste artigo.

Declaração de autoria e especificação das contribuições (declaration of authorship): todas e somente as pessoas que atendem os requisitos de autoria deste artigo estão listadas como autores; todos os coautores se responsabilizam integralmente por este trabalho em sua totalidade.

Declaração de ineditismo e originalidade (declaration of originality): a autora assegura que o texto aqui publicado não foi divulgado anteriormente em outro meio e que futura republicação somente se realizará com a indicação expressa da referência desta publicação original; também atesta que não há plágio de terceiros ou autoplágio. 
Dados do processo editorial

(http://www.ibraspp.com.br/revista/index.php/RBDPP/about/editorialPolicies)

- Recebido em: 08/12/2017

Equipe editorial envolvida

- Controle preliminar e verificação de plágio: 09/12/2017

- Avaliação 1: 23/12/2017

- Avaliação 2: 30/12/2017

- Editor-chefe: 1 (VGV)

- Editor-associado: 1 (GHB)

- Revisores: 2

- Decisão editorial preliminar: 10/01/2018

- Retorno rodada de correções 1: 18/01/2018

- Decisão editorial final: 18/01/2018

\section{COMO CITAR ESTE ARTIGO:}

SÁNCHEZ-RUBIO, Ana. Los peligros de la probabilidad y la estadística como herramientas para la valoración jurídico-probatoria. Revista Brasileira de

Direito Processual Penal, Porto Alegre, vol. 4, n. 1, p. 183-214, jan./abr. 2018.

https://doi.org/10.22197/rbdpp.v4i1.118

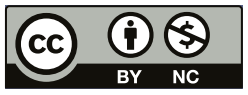

Esta obra está licenciada com uma Licença Creative Commons Atribuição-NãoComercial 4.0 Internacional. 